Blanco-Barrera, Ramón.

Profesor e Investigador en Formación, Universidad de Sevilla, Departamento de Dibujo.

\title{
La evolución del arte actual en un contexto de crisis.
}

\section{The evolution of contemporary art in a crisis context.}

TIPO DE TRABAJO:

Póster.

PALABRAS CLAVE:

Arte, contemporaneo, mercado, crisis.

KEY WORDS:

Art, contemporary, market, crisis.

RESUMEN

En los últimos tiempos, el arte actual se ha estado nutriendo del capital económico generado en un sistema utópico del bienestar que se volvió insostenible. Un sistema donde la competitividad es el modelo de negocio de cualquier empresa y donde el arte actúa como cualquier otro agente más, al son que marca el dólar.

Este trabajo tiene como objetivo escudriñar todo este entramado del mundo artístico contemporáneo a través del big data como concepto metodológico. Se identifican y analizan los actores que mueven el dinero del arte, desde la celebración de grandes eventos a la organización de inversiones especulativas, pasando por las casas de subastas. Se seleccionan y nombran algunos de éstos y se realiza una comparativa con las nuevas tendencias cambiantes experimentadas a raíz de la crisis.

A modo de conclusión, se vislumbra cómo, a su vez, este mundo del arte está comenzando a cambiar en una especie de intento por volver a sus orígenes de finalidad más social. Sin duda, un evento de cambio acelerado también por la influencia de las nuevas tecnologías de la información y comunicación digital.

\section{ABSTRACT.}

In recent times, modern art has been nourished by the economic capital generated in a utopian welfare system that became unsustainable. A system where competitiveness is the business model of any company and where art acts like any other agent, to the sound that dollar marks.

The aim of this work is to search all this structure of contemporary artistic world through the big data as a methodological concept. It identifies and analyzes the actors that move the money of the art, from the celebration of big events to the organization of speculative investments, passing through the auction houses. Some of these are selected and named and a comparison is made with the new changing trends experienced as a result of the crisis.

As conclusion, it is understood how, in turn, this world of art is beginning to change in a kind of attempt to return to its origins of more social purpose. Undoubtedly, an event of accelerated change also by the influence of new technologies of information and digital communication. 


\section{CONTENIDO.}

\section{INTRODUCCIÓN.}

Desde siempre las representaciones artísticas han ocupado un lugar capital en la forma de entender la vida. Hoy en día el reconocimiento del arte es tal que la revalorización del mismo está por las nubes. Como cualquier otro negocio, se ha convertido en un objeto de compraventa dentro de un sistema económico-social inabarcable. Mucha es la gente que cree que la adquisición del buen arte o de calidad, está al alcance de pocos, pero sin embargo, no más lejos de la realidad, esto se ha convertido en un mito no real infundado por los grandes tiburones del sector. Sin ir más lejos, en 2013 el precio medio de una obra de arte hecha por un artista de renombre y vendida en España rondaba los 3.500 euros (McAndrew 2014, p. 17), una cantidad presumiblemente asumible por cualquier público modesto.

Así lo pensaba Theodor Adorno cuando vio que nacía ante sus ojos, en los años treinta, una forma de arte que en realidad era una industria cultural (Adorno y Horkheimer 1988). Desde dicho enfoque, las masas, además de participar en la actividad artística, consumen, sea a través de la compra de productos y/o realizando actividades dotadas de cierto prestigio, sin que necesariamente tengan que llegar a comprender el significado último de las obras artísticas (Cruz 2012, p. 3).

En este trabajo se estudia la estructura mercantil artística contemporánea a través de la guía de datos estadísticos. Para ello, se analizan algunos de los sectores que manejan el arte actual y se establecen ciertas conclusiones en torno a las tendencias evolutivas que adoptan en función de otros factores externos como la crisis financiera o el boom tecnológico.

\section{DESARROLLO.}

El mercado del arte global es un mercado profundo de gran envergadura, que además está en continuo crecimiento. Tanto que en 2011 superó por primera vez en su historia los 10.000 millones de dólares, llegando a alcanzar la friolera cifra de 11.500 millones de dólares (Pérez 2012, p. 1). Un récord histórico que viene acompañado por otro, ya que de estas ventas en 2011, alrededor del $10 \%$ fue íntegramente en arte contemporáneo, superando por primera vez los 1.000 millones de euros en un ejercicio y cuyo progreso en ventas creció un $15 \%$ entre los años 2012 y 2013 de forma internacional (AFP 2013, p. 1). En términos de tamaño, el mercado español puede clasificarse como un mercado del tramo medio, en crecimiento y en auge (McAndrew 2012, p.16).

Existe una tendencia de crecimiento en todo el mundo respecto a la consolidación de grandes eventos artísticos como ferias de arte contemporáneo, bienales o apertura de nuevas galerías. Sólo en España, fijando nuestra mirada en la ciudad de Málaga, hace pocos años no destacaba por sus instituciones de arte, y sin embargo hoy tiene el Museo Picasso, el Museo Carmen Thyssen y el primer Museo Pompidou fuera de Francia (VV.AA. 2013), entre otros espacios dedicados al arte contemporáneo, situando a Málaga como un foco artístico moderno importante y de referencia nacional.

Por otro lado, si confiamos en la estadística que elaboran las casas de subastas, en los últimos años se observa un crecimiento estable del mercado del arte, batiendo récords de precios y con coleccionistas activos tanto en las ventas abiertas como en el transcurso de acuerdos particulares (Apresián 2013, p. 1). Un aumento que parece no estar afectado por la crisis económica. De hecho, en vez de caer empicado, sale reforzado, puesto que, como con los inmuebles materiales, la obra de arte se revaloriza y debido a la bajada de precios provocada por la crisis, significa una inversión muy rentable y jugosa a largo plazo, haciendo que aumenten de este modo las inversiones especulativas (McAndrew en Carbajo 2010, p. 1).

Por otro lado, las crisis también motivan la creatividad y el cambio, proporcionando nuevas formas de pensamiento más colaborativas para conseguir mayores logros (EFE 2012). Se generan por tanto nuevos escenarios de transmisión de conocimiento y resurgimiento social, acudiendo a la tecnología como apoyo para crear mecanismos alternativos, como plataformas de crowdfunding o el intercambio y difusión a través de las redes sociales.

\section{CONCLUSIONES.}

Podemos observar que el mercado del arte es un sector vivo que evoluciona en aumento en situaciones normales, pero que además es capaz de adaptarse al cambio en otros contextos como en las crisis, reinventándose y utilizando todas las herramientas a su alcance para ello, como las tecnologías digitales. El arte pues, sumergido en estas circunstancias, también parece abrirse hacia lo social, adaptando un nivel de consumo proporcional y accesible a cualquier estrato poblacional. 


\section{FUENTES REFERENCIALES.}

ADORNO, Th.; HORKHEIMER, M. 1988. La industria cultural. Iluminismo como mistificación de masas. Buenos Aires: Ed. Sudamericana.

AFP. 2013. "Récord histórico" para el mercado del arte contemporáneo. En Estrategia\&Negocios, Centroamérica, 7 oct. 2013.

[Consulta 10 enero 2014] Disponible en: http://www.estrategiaynegocios.net/blog/2013/10/07/record-historico-para-el-mercado-delarte-contemporaneo/

APRESIÁN, A. 2013. Tendencias del mercado internacional del arte en 2013. En La Voz de Rusia, Moscú, 31 jul. 2013. [Consulta 3 enero 2014] Disponible en: http://spanish.ruvr.ru/2013_07_31/Rumbos-del-mercado-internacional-del-arte-7397/

CARBAJO, M. 2010. Los mercados del arte contemporáneo se recuperan tras la crisis. En Eastwind: global business, cultura \& lifestyle, [Consulta 19 diciembre 2013] Disponible en: http://www.eastwind.es/newsletter_detalle.php?id=2009

CRUZ, B. 2012. Arte y Sociedad: ¿una relación en crisis?. En Razón y Palabra, № 79, México D.F. [Consulta 19 diciembre 2013]

Disponible en: http://www.razonypalabra.org.mx/N/N79/V79/64_Cruz_V79.pdf

EFE. 2012. Los expertos apelan a la creatividad para animar a los emprendedores. En Inversión \& Finanzas, Noticias, Madrid, 27 oct. 2012. [Consulta 15 abril 2013] Disponible en: http://www.finanzas.com/noticias/economia/20121027/expertos-apelan-creatividadpara-1592785.html

MCANDREW, C. 2012. El Mercado Español del Arte en 2012. Barcelona: Ed. Fundación Arte y Mecenazgo.

MCANDREW, C. 2014. El Mercado Español del Arte en 2014. Barcelona: Ed. Fundación Arte y Mecenazgo.

PÉREZ, C. 2012. El mercado del arte supera por primera vez los 10.000 millones de dólares en 2011. En rtve Noticias, Madrid, 17 mar. 2012. [Consulta 3 diciembre 2016] Disponible en: http://www.rtve.es/noticias/20120317/mercado-del-arte-supera-primera-vez10000-millones-dolares-2011/507483.shtml

VV.AA. 2013. Málaga aumenta su oferta museística con el primer Centro Pompidou fuera de Francia. En Arteinformado, 29 nov. 2013. [Consulta 10 enero 2017] Disponible en: http://www.arteinformado.com/Noticias/3812/malaga-aumenta-su-oferta-museistica-con-elprimer-centro-pompidou-fuera-de-francia/ 